\title{
SIMULATION OF HYDRAULIC CIRCUITS BY USING
}

\section{MATLAB - SIMULINK SOFTWARE}

\section{SANTHOSH KUMAR. R, MNVRL. KUMAR \& SIREESHA KONERU}

Department of Mechanical Engineering, Koneru Lakshmaiah Education Foundation,

\author{
Vaddeswaram, Andhra Pradesh, India
}

\begin{abstract}
Hydraulic actuators can be used in large number of applications like machinery, automobiles, robot mechanical design etc. in present work we choosen closed loop Electro-hydraulic actuator with proportional valve coupled with a feedback system. The time response of the hydraulic actuator is notable especially when it is used for lifting the load. In this view estimating the time response of the hydraulic actuator prior to its usage is going to be very useful to analyze the Effectiveness of the system. Which will also useful to get an optimum design parameters for hydraulic actuator. In the Present work a position control electro-hydraulic linear actuator was choosen which can be used for Monitoring the movements of loads. Numerical Calculations of the hydraulic actuator and its components is done by using the mathematical equations. Matlab/Simulink Software is used to obtain the time response of the linear actuator
\end{abstract}

KEYWORDS: Hydraulic Actuators, Simulation \& Time Response

Received: Feb 18, 2019; Accepted: Mar 08, 2019; Published: Jun 12, 2019; Paper Id.: IJMPERDJUN2019173

\section{INTRODUCTION}

Nowadays most of the machines using in industries are multi-axis machines in that many of them, especially of large power are operating with electro-hydraulic power and Monitored by proportional or servo valves.

Motion in every axis need to be operated in an open or closed loop control environment, based on the level of accuracy requirment, and the features of the instruments were implemented in the system. In many situations the cycle motions are slow and not require high accuracy and the devices used are showing stable and close to linear characteristics. In these cases, an open loop control system would be a Convenient, simple and Economic solution. A closed loop control system is useful when the system dynamics is skittish and the expected level of accuracy is high.

\section{PROBLEM DEFINITION}

The main aim of this paper is designing a new electro hydraulic actuator for lifting 1 ton of load. Electro hydraulic actuator means we give the electrical signal as input according to this signal the actuator runs. Based on the Actuator design we should select the pump, pipe, directional valve, proportional valve, and spring mass system parameters according to performance characteristics. After we find out the acceleration time response it is Equated with the real time response graphs to know the similarity. 


\section{MECHANICAL SETUP OF ELECTRO HYDRAULLY OPERATED ACTUATOR}

\section{Description of Hydraulic Components}

The following subsections comprise a short description of the Principal Hydraulic parts that structure a typical position controlled system

- Supply of Hydraulic Power

- Valve to Control Flow

- Linear Hydraulic Actuator

- Pump

\section{EXPERIMENTAL RESULTS \& VALIDATION}

Numerical Statistics used in the Present Study

For Actuator

The cylinder Design Diagram is shown in Appendix

$\begin{array}{lll}\text { Piston Cylinder Diameter D } & =100 \mathrm{~mm} \\ \text { Area of the Cylinder } \mathrm{A}_{1} & =\left(\pi \mathrm{d}^{2} / 4\right) & =7853.88 \mathrm{~mm}^{2} \\ \text { Rod end cylinder diameter } \mathrm{d} & =70 \mathrm{~mm} \\ \text { Rod end cylinder area } \mathrm{A}_{2} & =3848.45 \mathrm{~mm}^{2} \\ \text { Net Area A } & =706.85 \mathrm{~mm}^{2} \\ \text { Total stroke length } & =2600 \mathrm{~mm}\end{array}$

Pipe Data

$\begin{array}{ll}\text { Pipe Diameter } & =30 \mathrm{~mm} \\ \text { Thickness } & =3 \mathrm{~mm} \\ \text { Pipe length } & =5 \mathrm{~m}\end{array}$

Pump Data

Pump Performance Characteristics Provided in Appendix

$\begin{array}{ll}\text { Pump Displacement } & =131.1 \mathrm{Cm}^{3} / \mathrm{rad} \\ \text { Pump Speed } & =1500 \mathrm{rpm} \\ \text { Power } & =45 \mathrm{KW}\end{array}$

Spring Mass System Data
Mass
$=1000 \mathrm{~kg}$
Spring rate
$=15000 \mathrm{~N} / \mathrm{m}$ 


\section{SIMULINK MODEL}

Below Figure Shows the Simulink model of the chosen actuator. The model diagram is designed; the design process and selection of parameters are described. The actuator model diagram is constructed by individual blocks are drag from the Simulink library browser to the main window and connect this blocks according to fluid flow. Finally to observe the time response of the Actuator we connected a device called scope block. The detailed information about individual blocks is represented. Then after input signal is arranged in the signal builder as per our requirements. And edit the individual blocks and enter the parameter values. Start simulation process by click on the start symbol, after completion of the simulation process we can see the results on scope block as a graph of the Actuator motion with respect to time.

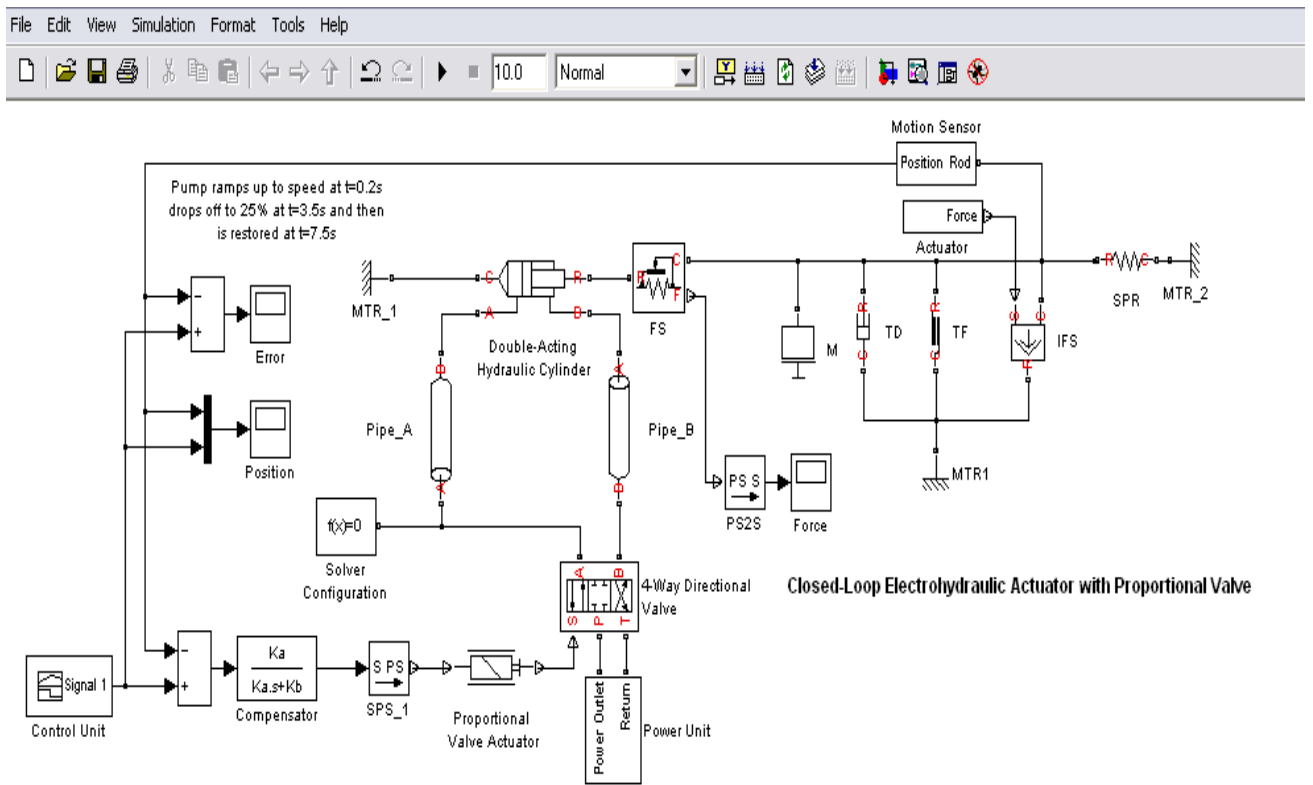

Figure 1: Simulink Model of Hydraulic System

After completion of simulation process, we will get the Time Response of the Actuator motion in Graph in MATLAB- SIMULINK. The results are shown in below figure.

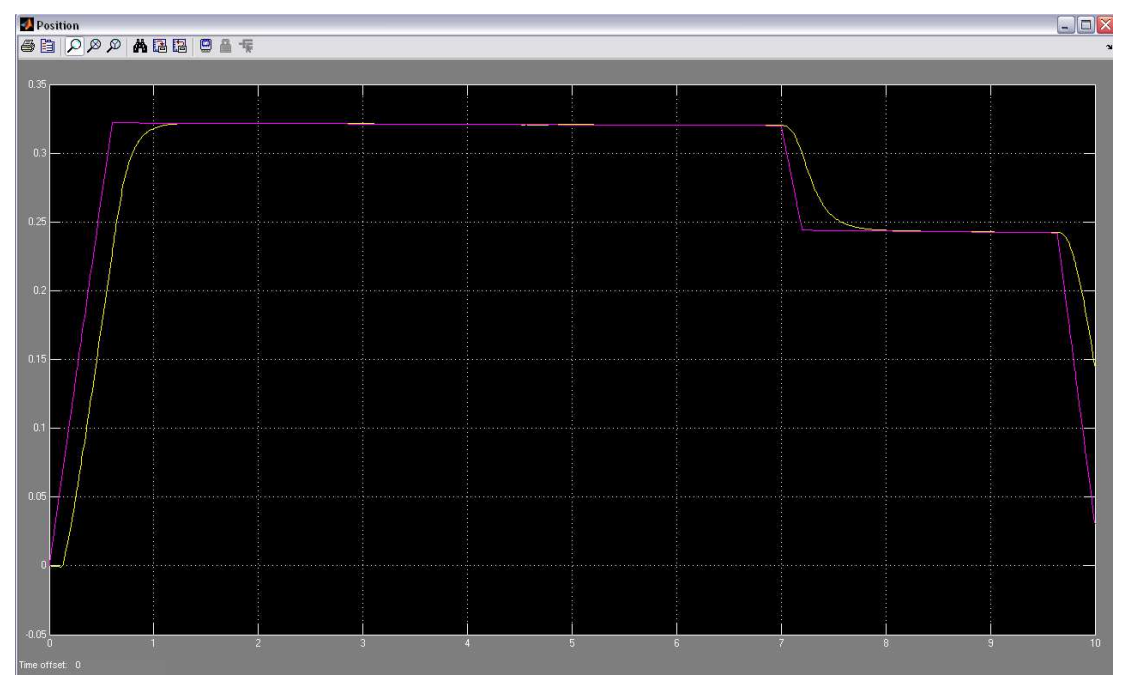

Figure 2: Time Response of Actuator Motion Graph 
In the above graph Pink color line represents the input and yellow color line represents the output

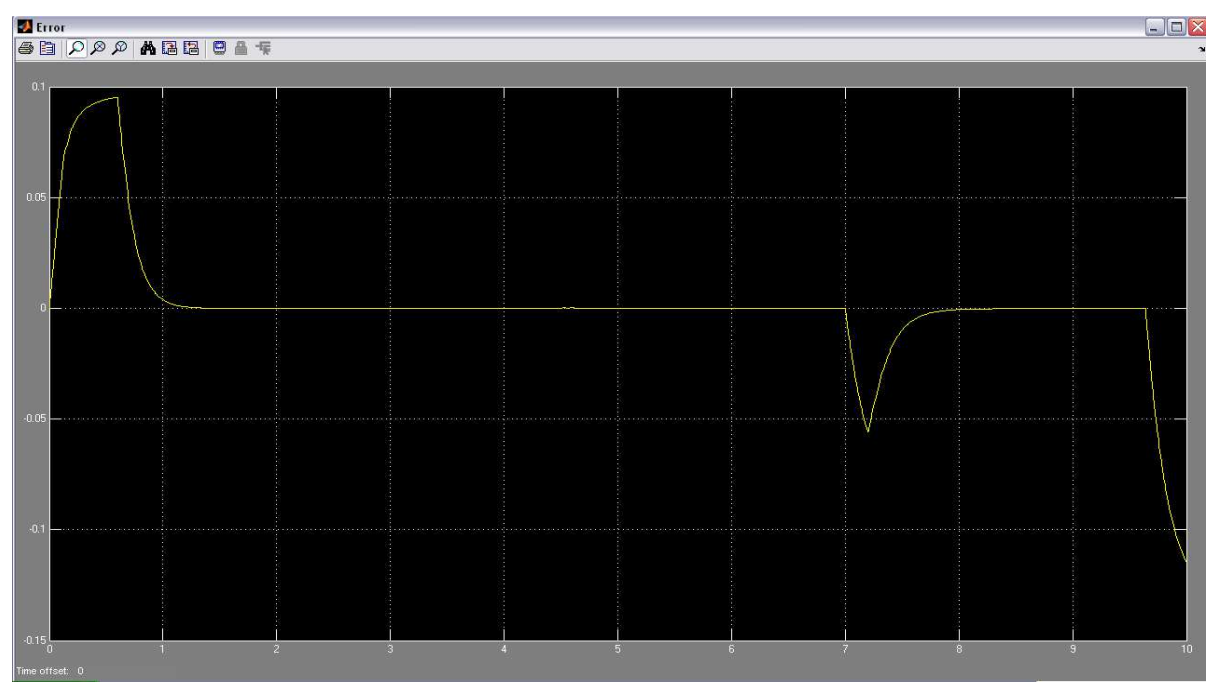

Figure 3: Error Graph

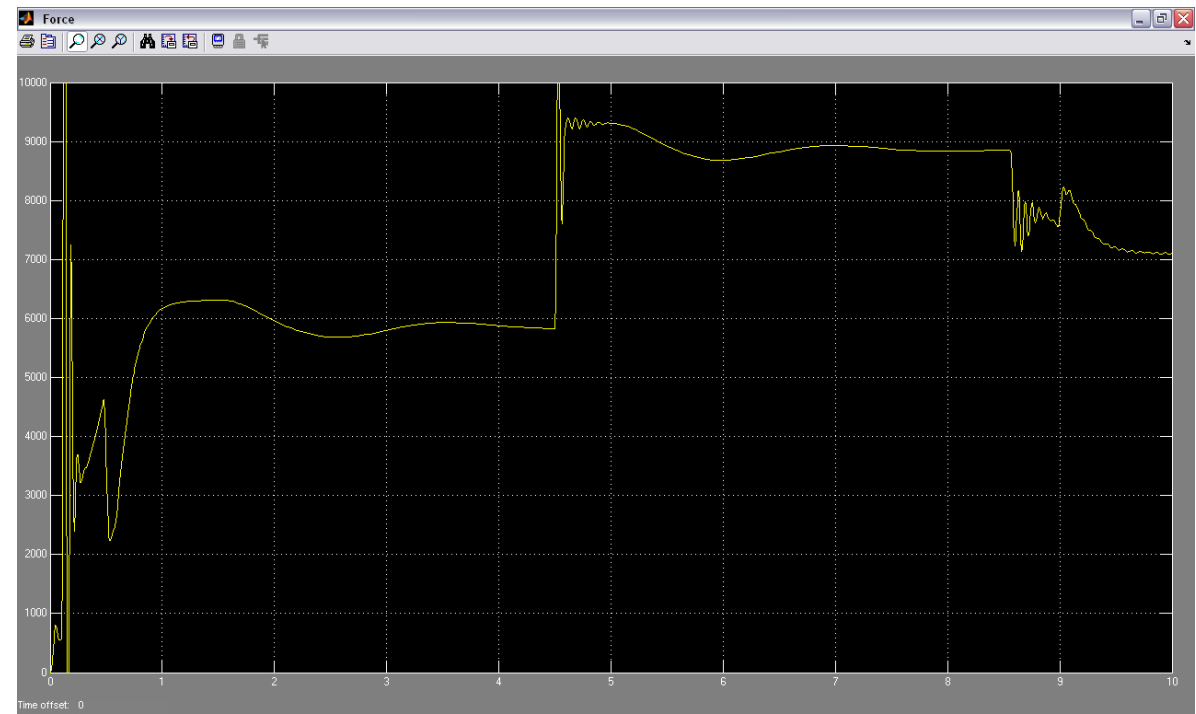

Figure 4: Force Acting on the Actuator

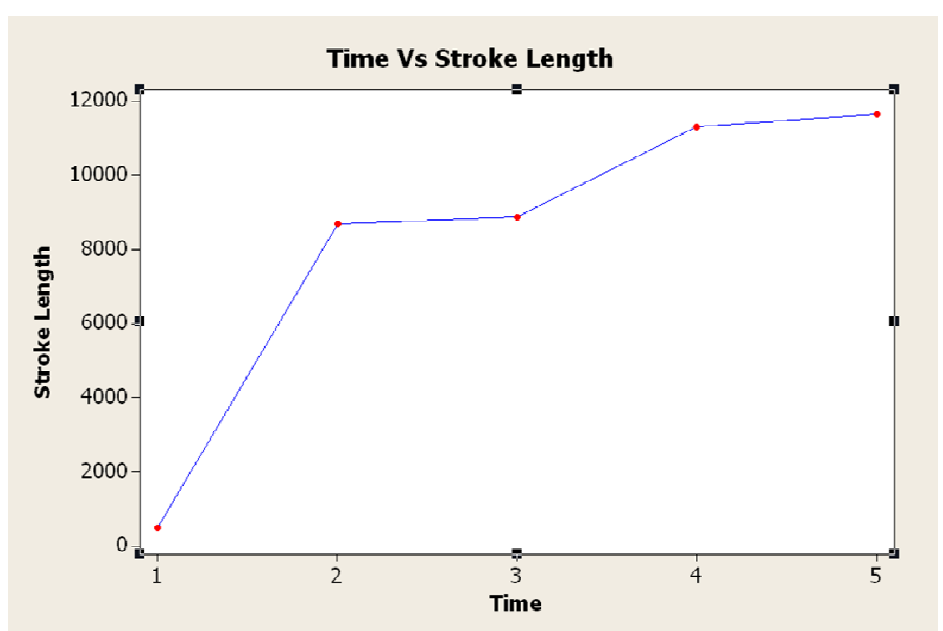

Figure 5: Time Vs Stroke Length Graph 


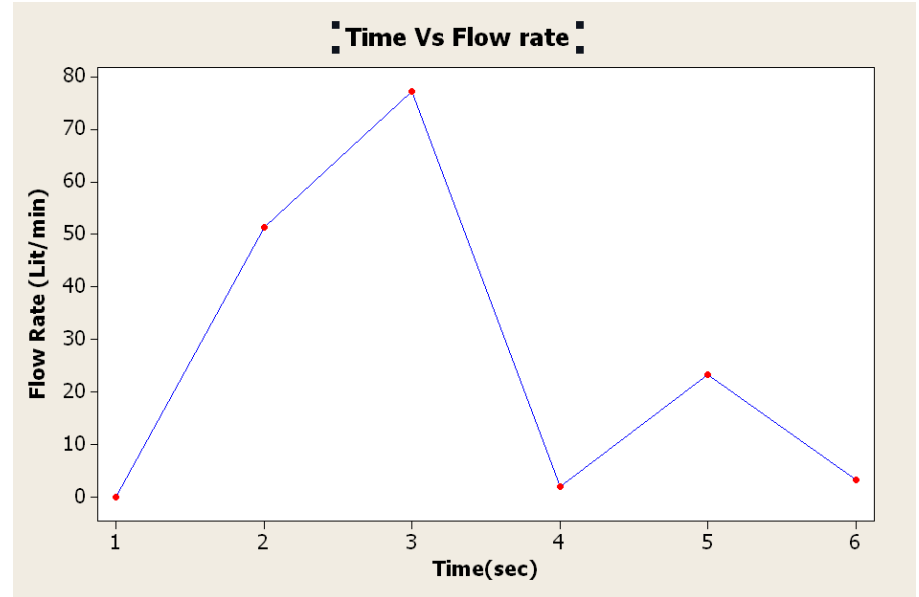

Figure 6: Time Vs Flow Rate Graph

Below figure shows the Real time Response graph of the Actuator from the Experimental Data

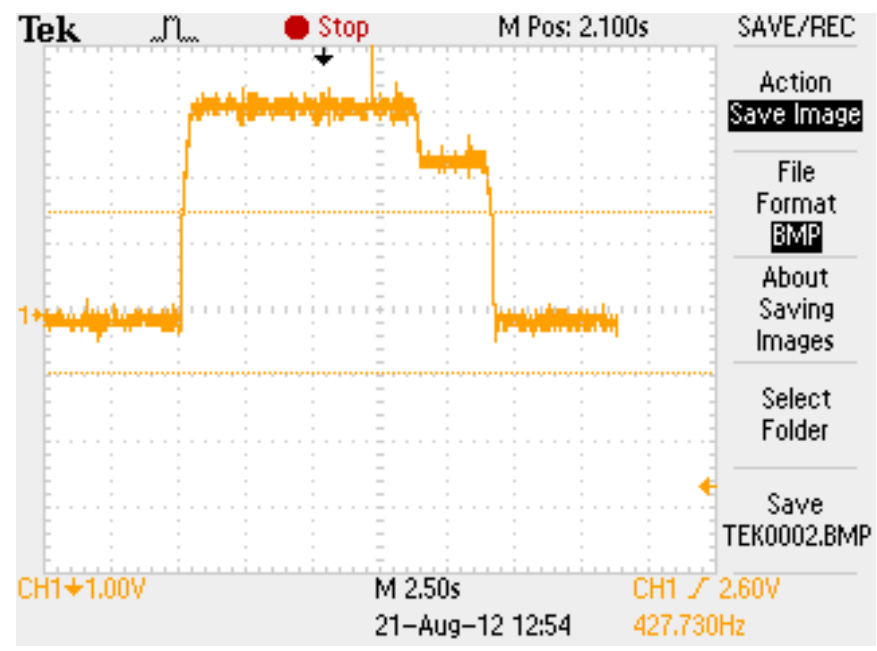

Figure 7: Real time Graph of the Actuator Shifting Forward

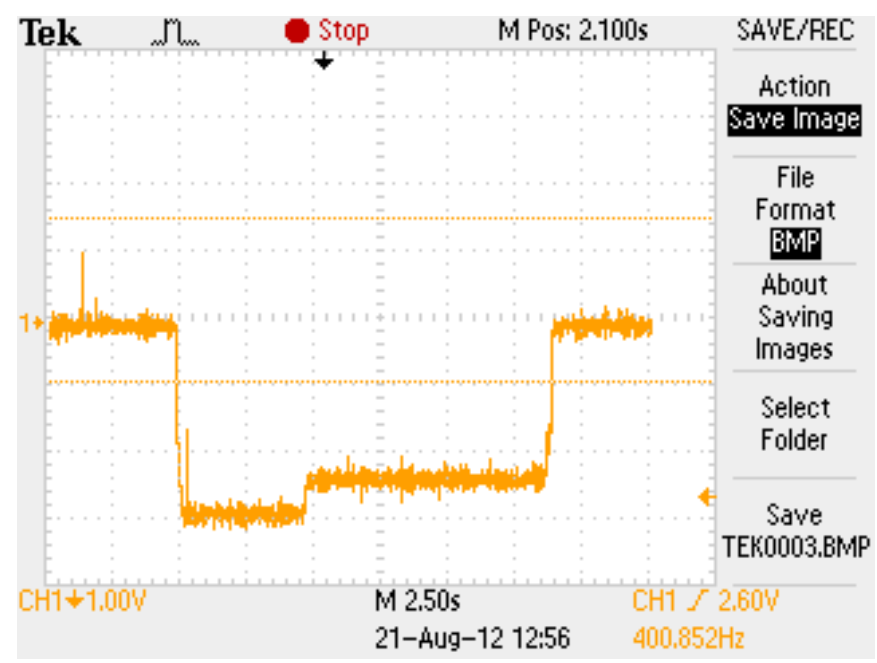

Figure 8: Real time Graph of the Actuator Shifting Backward 


\section{Determination of Unknown Parameter}

Acceleration and deceleration times are the unknown parameter. Here we should find out the acceleration time from the resultant graphs.

\section{Hydraulic Cylinder Calculations}

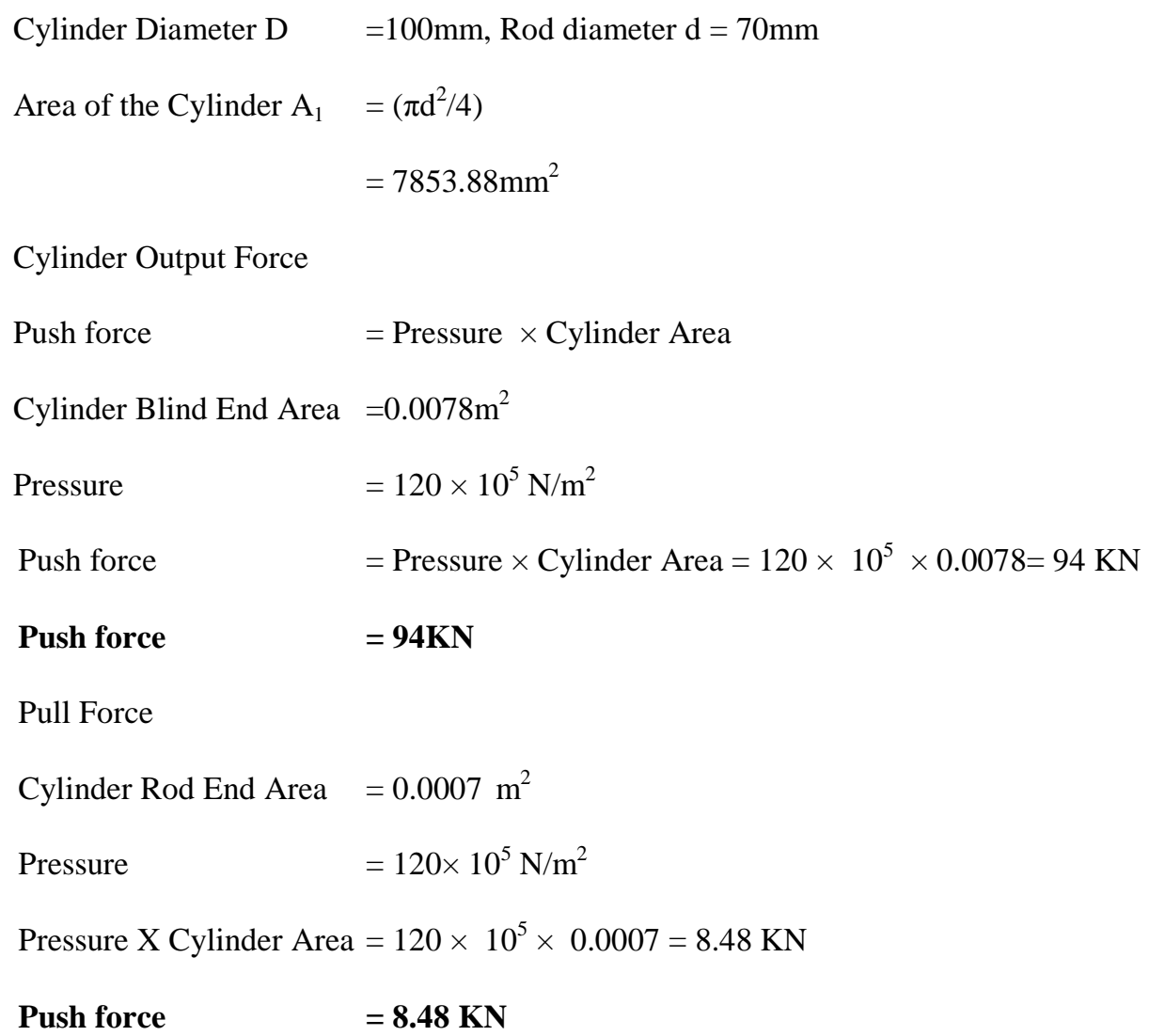

\section{Pipe Calculations}

$\begin{array}{ll}\text { Pipe diameter } & =0.027 \mathrm{~m} \\ \text { Area } & =5.762 \times 10^{-4} \mathrm{~m}^{2} \\ \text { Geometrical Shape factor } & =64 \text { (circular) } \\ \text { Reynolds number } \mathrm{R}_{\mathrm{e}} & =\rho \mathrm{vd} / \mu \\ \text { Velocity v } & =227 \mathrm{~m} / \mathrm{s} \\ \text { Density of the fluid } \rho & =961.8 \\ \text { Viscosity } \mu & =7.1283 \mathrm{cst} \\ \mathrm{R}_{\mathrm{e}} & =\rho \mathrm{vd} / \mu \\ \mathrm{R}_{\mathrm{e}} & =961.8 \times 227 \times 0.027 / 7.1283 \\ & =826.96<2000 \text { the flow is laminar }\end{array}$


Friction factor $(\mathrm{f})=64 / \mathrm{R}_{\mathrm{e}}=0.07$

Step 1

Divide the total stroke length into no divisions as follows

Assume stoke lengths and time from this we should find acceleration

Stroke lengths $S_{1}=109 \mathrm{~mm}$, Time $t_{1}=480 \mathrm{~ms}=0.48 \mathrm{~s}$

$\mathrm{S}_{2}=1818 \mathrm{~mm}$, Time $\mathrm{t}_{2}=8.2 \mathrm{Sec}$

$\mathrm{S}_{3}=46 \mathrm{~mm}$, Time $\mathrm{t}_{4}=200 \mathrm{~ms}$

$\mathrm{S}_{4}=550 \mathrm{~mm}$, Time $\mathrm{t}_{1}=2.42 \mathrm{Sec}$

$\mathrm{S}_{5}=77 \mathrm{~mm}$, Time $\mathrm{t}_{1}=340 \mathrm{~ms}$

\section{Step 2}

Velocity $\mathrm{V}_{1} \quad=\mathrm{S}_{1} / \mathrm{t}_{1}$ $=109 / 480=227.08 \mathrm{~m} / \mathrm{s}$

$S=\frac{1}{2} a t^{2}$

$0.109=0.5 \times \mathrm{a} \times(0.48)^{2}$

$a=946 \mathrm{~mm} / \mathrm{s}^{2}$

Flow rate $=$ volume $/$ unit time

Volume $=\pi R^{2} h$

$$
=\pi \times(0.05)^{2} \times 0.109=8.56 \times 10^{-4} \mathrm{~m}^{3}
$$

Flow rate $\mathrm{f}_{1}=8.56 \times 10^{-4} \mathrm{~m}^{3} / \mathrm{s}$

$$
=8.56 \times 10^{-4} \times 1000 \times 60=51.36 \mathrm{lit} / \mathrm{min}
$$

Flow rate $f_{1}=51.36 \mathrm{lit} / \mathrm{min}$

$s=\frac{1}{2} a t^{2}$

From acceleration and stroke length we calculate the time

$$
\begin{aligned}
& \text { Time } \mathrm{t}_{1}=\sqrt{\frac{2 s}{a}} \\
& =\sqrt{\frac{2 \times 109}{946}}=480 \mathrm{~ms}
\end{aligned}
$$

Acceleration time $t_{1}=\mathbf{4 8 0} \mathbf{~ m s}$ 


\section{Step 3}

Flow rate $=$ volume $/$ unit time

Volume $=\pi(\mathrm{R}-\mathrm{r})^{2} \mathrm{~h}$

$=\pi \times(0.015)^{2} \times 1.818=1.285 \times 10^{-3} \mathrm{~m}^{3}$

Flow rate $\mathrm{f}_{2}=1.285 \times 10^{-3} \mathrm{~m}^{3} / \mathrm{s}$

$=1.285 \times 10^{-3} \times 1000 \times 60=77.1 \mathrm{lit} / \mathrm{min}$

Flow rate $f_{2}=77.1 \mathrm{lit} / \mathrm{min}$

\section{Step 4}

From deceleration and stroke length we calculate the time

Time $t_{3}=\sqrt{\frac{2 g}{a}}$
$=\sqrt{\frac{2 X 46}{1150}}=200 \mathrm{~ms}$

Flow rate $=$ volume $/$ unit time

Volume $=\pi(\mathrm{R}-\mathrm{r})^{2} \mathrm{~h}$

$=\pi \times(0.015)^{2} \times 0.046=3.25 \times 10^{-5} \mathrm{~m}^{3}$

Flow rate $\mathrm{f}_{3}=3.25 \times 10^{-5} \mathrm{~m}^{3} / \mathrm{s}$

$=3.25 \times 10^{-5} \times 1000 \times 60=1.95 \mathrm{lit} / \mathrm{min}$

Flow rate $f_{3}=1.95 \mathrm{lit} / \mathrm{min}$

Step 5

Flow rate $=$ volume $/$ unit time

Volume $=\pi(\mathrm{R}-\mathrm{r})^{2} \mathrm{~h}$

$=\pi \times(0.015)^{2} \times 0.55=3.88 \times 10^{-4} \mathrm{~m}^{3}$

Flow rate $\mathrm{f}_{4}=3.88 \times 10^{-4} \mathrm{~m}^{3} / \mathrm{s}$

$=3.88 \times 10^{-4} \times 1000 \times 60=23.32 \mathrm{lit} / \mathrm{min}$

Flow rate $\mathbf{f}_{4}=23.32 \mathrm{lit} / \mathrm{min}$

Step 6

Flow rate $=$ volume $/$ unit time

Volume $=\pi(\mathrm{R}-\mathrm{r})^{2} \mathrm{~h}$

$=\pi \times(0.015)^{2} \times 0.077=5.44 \times 10^{-5} \mathrm{~m}^{3}$ 
Flow rate $\mathrm{f}_{5}=5.44 \times 10^{-5} \mathrm{~m}^{3} / \mathrm{s}$

$$
=5.44 \times 10^{-5} \times 1000 \times 60=3.26 \mathrm{lit} / \mathrm{min}
$$

\section{Flow Rate $\mathbf{f}_{5}=3.26 \mathrm{lit} / \mathrm{min}$}

For the same simulation model diagram different types of input signal are given example sine wave and step signal. The actuator motion is observed and the resultant graph are shown in below figures.

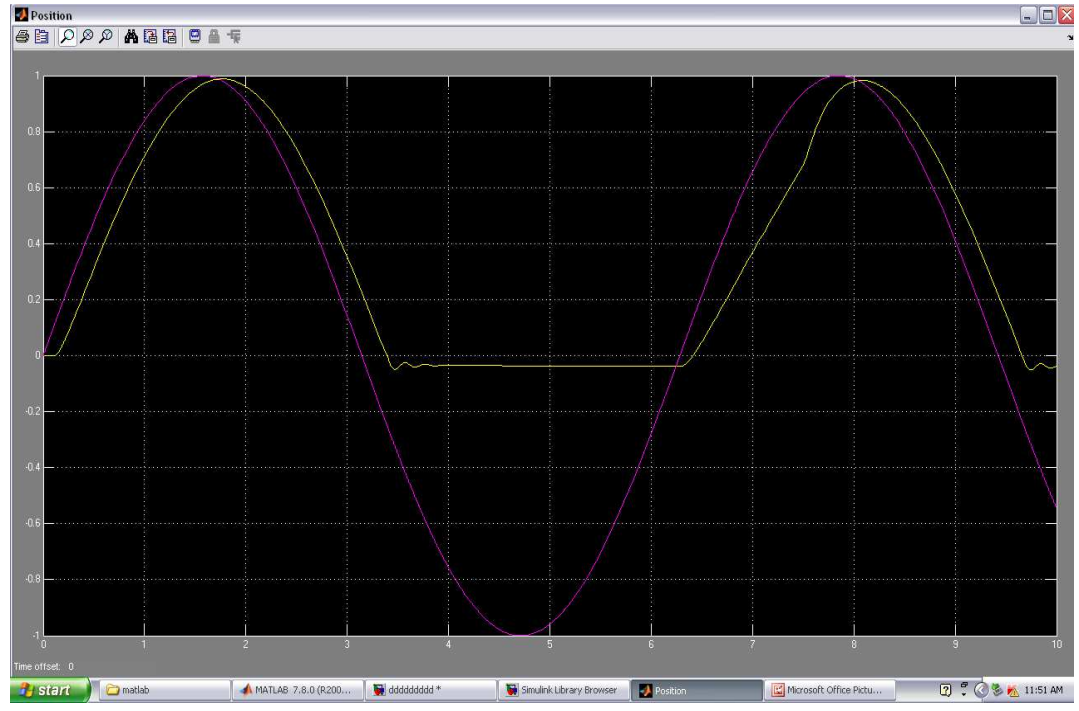

Figure 9: Time Response Graph of the Actuatot, Sine Wave is Given as Input Signal

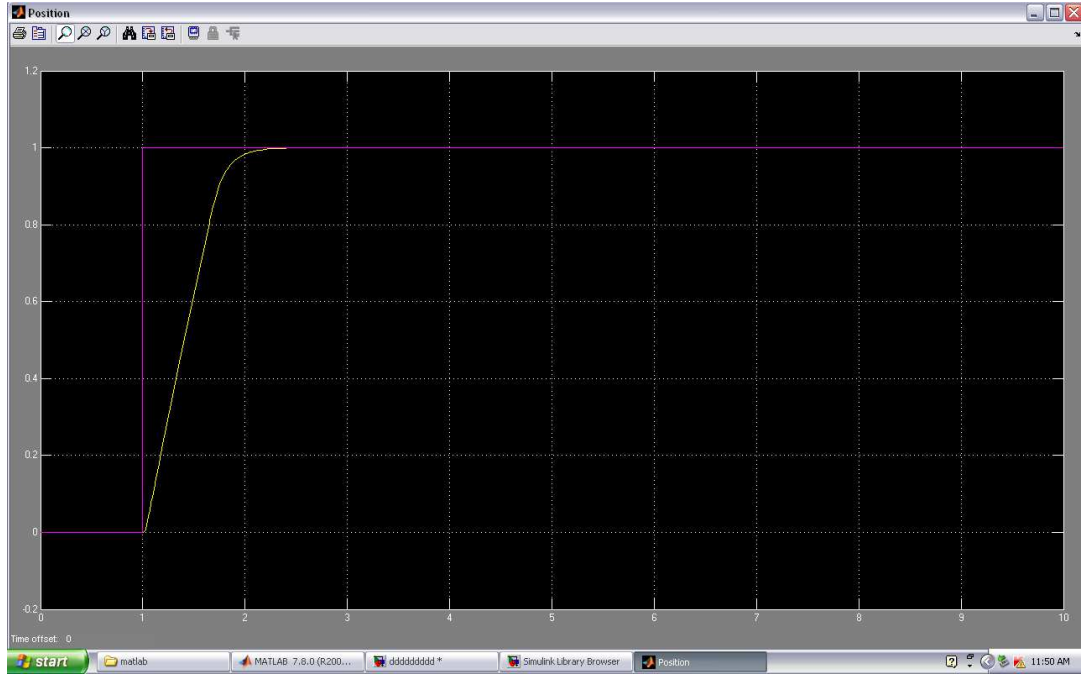

Figure 10: Time Response Graph of the Actuator, Step Signal is given as Input Signal

\section{RESULTS AND DISCUSSIONS}

In this case Study a step signal is given as sign. The actuator that designed by choosing the parameters from the product chart. The time response was acquired from the scope block through MATLAB/SIMULINK software. The time response of a system is the way in which it acts with respect to time and which plays a vital role for assessing the system performance. Time responses was plotted as time on the Horizontal axis( X-axis) and Amplitude on the vertical axis (Yaxis). The time response of an actuator was shown in the above Figures, 
The schematic Diagram of Electro hydraulic actuator was shown in Figure 1 and Figure 2 represents the time response of the Actuator which shows an adequate balance between rise time and overshoot. The acquired time response is also compared with the time response graphs acquired from experimental studies of electro-hydraulic actuator, which were represented in above figures and both were found to be in good compromise.

\section{CONCLUSIONS}

Mathematical models were implemented for the hydraulic parts like hydraulic actuator, piston chambers, proportional valve and variable displacement pressure compensated pump as per the system requirements, properties of the flowing fluid and system characteristics,. This time response is a very important factor for critical system like a motion control actuator.

- These Simulink models of hydraulic actuator work like a virtual hydraulic actuator and we can acquire the response of the system with respect to time while not physically testing the mechanism.

- The time response of the electro hydraulic actuator is acquired by using the MATLAB/SIMULINK software.

- By using the above said models the performance of the hydraulic parts, like pump and proportional valve etc can be monitored.

- By variable the scheme parameters like pressure, active annulus area, stroke length, control current etc the designer will gain optimum parameters of the hydraulic mechanism.

- With the help of these MATLAB/SIMULINK models of electro hydraulic actuator the time response of the hydraulic mechanism will be obtained while not physically testing the mechanism

- The time responses obtained from the simulation are compared with the Experimental hydraulic actuator data and found to be in Coinciding.

\section{REFERENCES}

1. Design and Modelling of a new electro hydraulic actuator by Vladimir Pastrakuljic in this thesis new electro hydraulic actuator is designed and simulated using MATLAB - SIMULINK software.

2. Simulation of Electro Hydraulic Actuator by Servo Actuator by Vijaya Sagar Tenali, National Institute of Technology, Rourkela Rourkela(Orissa)

3. Joshi, A. and Pramodh, Modelling and Simulation of Launch Vehicle Digital Autopilot, AIAA Paper No. 4696, Proc. Of .Modelling and Simulation Technologies Conference, Monterey, CA, USA, August 2002

4. Holger Berndt, Interactive Design and Simulation Platform for Flight Vehicle Systems Development, IEEE Transactions on Control Systems Technology, Vol. 12, No. 2,March 2004, pp. 250-262.

5. Peter Rowland, M. Longvitt modular design approach for modeling of large and complex hydraulic systems, International journal of fluid power, volume 12, number 4,August 2005, pp 134-152.

6. R.H.Maskrey and W.J.Thayer, a Brief History of Electro hydraulic Servomechanisms, Moog Technical Bulletin 141, June 1978.

7. T. P. Neal, Performance Estimation for Electro hydraulic Control Systems, Moog Technical Bulletin126, November 1974

8. J.C.Jones, Developments in Design of Electro hydraulic Control Valves, Moog Technical Paper, November 1997 
9. DeRose, the Expanding Proportional and Servo Valve Marketplace, Fluid Power Journal, March/April 2003.

10. A Systematic Methodology for Optimal Component Selection of Electro hydraulic Servo Systems, International Journal of Fluid Power, volume 5, Nov 2004.

11. Guillon M, Hydraulic Servo Systems Analysis and Design, Butterworth \& Co Ltd., 1969.

12. Viersma, T. J., Analysis, Synthesis and Design of Hydraulic Servosystems and Pipelines, Elsevier Scientific Publishing Company, 1980.

13. Raghu, N., Tejaswini, G. V., \& Aparna Rao, S. L. (2013). Simulation of 13 Panels Phased Array Antenna by Using STK Tool. International Journal of Electronics and Communication Engineering.

14. Merritt, Herbert E., 1967, Hydraulic Control Systems, Wiley, New York. M. J. Tonyan and T. Goldoftas, electronically controlled Proportional Valves Marcel Dekker Inc., 1985.

15. D. McCloy and H. R. Martin, ÇPPtrol of Fluid Power, John Wiley \& Sons 1980

16. H. Funakubo, Actuators for Control, Gordon \& Breach Science Publishers, New York, 1991.

17. Fabrication and testing for nanosatellite deployable mechanisms, Praveen Kumar, R., Manikanta, P., Kumar, M.N.V.R.L., Santhosh Kumar, R. International Journal of Mechanical and Production Engineering Research and Development (IJMPERD) ISSN(P): 2249-6890; ISSN(E): 2249-8001 Vol. 8, Issue 3, Jun 2018, 133-144 
